Scientific basis for practical conservation

Conservation in Practice. Edited by $\mathrm{A}$. Warren and F. B. Goldsmith. Pp. $x i x+512$. (Wiley: London and New York.) Cloth $£ 9.50$; paper $£ 4.50$.

AFTER fifteen highly successful years, the University College, London, MSc course in conservation is still alive and well, and residing in Bloomsbury, a fact which is demonstrated by the publication of this collection of essays written by many of those who have been involved in the development and teaching of this course. The term 'conservation' has taken upon itself a considerable breadth of meaning in recent years and this is reflected in the wide subject coverage of the thirty chapters in this book. These range over the control of weather, coastlines and floods, the preservation of genes, habitat management (including a number of case histories, for example, heathlands, woodlands and moorlands), pesticides and derelict land reclamation. There are accounts of historical approaches to subjects such as soil erosion, and experimental approaches to problems such as human trampling. And, of course, there are the inevitable accounts of the politics and administration of conservation.

Books could be written about any one of these subjects; indeed books have been written about most of these subjects. It is inevitable, therefore, that many of these short (average 15 pages) essays should be superficial. There are occasions when simplification is taken to the point of inaccuracy, but this is fortunately rare. Perhaps the most successful articles are those which do not attempt to summarise their entire subject, but concentrate on welldocumented examples from which general principles may be drawn. For this reason I found Hollis on river management, Norman Moore on pesticides and Vita-Finzi on soil erosion, particularly valuable. It is understandable that difficulties will arise when trying to write short articles on broad subjects aimed at "the layman as well as students, planners, and so on."

One might also question the use of the phrase in Practice in the title. Max Nicholson states proudly in the Foreword that the book "was written almost entirely by administrators, planners and official and university scientists without a park superintendent, a forester or a land manager among them". One wonders how this can begin to be a manual of practical conservation; in fairness, it is not. Rather it seeks to emphasise the necessity for a scientific basis for practical conservation.
On the political and administrative side, Nicholson's Foreword must rank as the most entertaining and frank contribution. He decries the recent splitting of the old Nature Conservancy and one cannot but sympathise with his views. One wonders, however, whether it might result in a greater research effort into the practical issues of conservation rather than theoretical ecology. Admittedly, it is difficult to separate the two-only Whitehall seems capable.

Overall, the book's greatest merit is that it draws into one volume contributions from such a variety of disciplines. Any student who picks up this book will find some fresh ideas and information from a field outside his immediate training and, in doing so, he will broaden his concept of conservation.

P. D. Moore

\section{Bumper book on cognition}

Exploration in Cognition. (A Series of Books in Psychology.) By Donald A. Norman and David E. Rumelhart. Pp. xvi 430. (Freeman: San Francisco, 1975.) \$13.50.

THIs is a sort of academic version of a Bumper Holiday Fun Book, recounting all the latest adventures of Professor Norman and his jolly chums by the sea in sunny San Diego. The chums are called the LNR Research Group and they are accompanied on their explorations by their pet computing system, MEMOD.

The book begins with a general discussion of the group's approach to the study of language and cognition, leading to a comparison of the mind with an "active structural network". The important characteristic of an active structural network is that it stores factual information-John is $6 \mathrm{ft}$ tall-in the same way that it stores knowledge about how to manipulate that information: how to find out whether John is taller than Bill. It is at the same time a table of facts, and a fiowchart for a program that can use the facts in the table to make further deductions. In computer programming terms, it erases the distinction between programs and data.

The group uses the terminology of active structural networks to formulate theories about the strategies we use to carry out various mental tasks, such as recognising faces and playing board games. They also write computer programs to simulate networks, and compare the performance of these programs with that of human subjects. MEMOD, whose name stands for "memory model", is specially designed to simulate active structural networks, and the book gives a clear discussion, at layman's level, of how it works.

In the last half of the book, various members of the group describe their own research projects. Palmer's discussion of ways in which knowledge of the world can guide visual perception, and Eisenstadt and Kareev's work on how people analyse board positions in the games of Go and Go Moku are especially interesting.

The main fault of the book as a whole is a tendancy to let theoretical discussions trail off inconclusively with remarks to the effect that more work needs to be carried out in the area. This seems to be connected with an unwillingness to set up any criteria by which we might judge the adequacy of the group's whole approach, and in particular the use of active structural networks. They are not bothered if a particular theory formulated in terms of these networks doesn't work very well, because they can always formulate another one instead.

Perhaps they are right not to worry. It is clear that there is some interesting work being done in San Diego, and this book conveys the feeling that they are having a good time doing it.

S. D. Isard

\section{Pictorial Key to Genera of Plant-Parasitic Nematodes}

\section{FOURTH EDITION, REVISED}

W. F. Mai and H. H. Lyon

The only work of its kind, this fully illustrated, easy-to-use manual will be indispensable to students and others who wish to identify nematodes. The descriptive key, full-page photographs, generic descriptions, and characteristics of genera will aid users in learning to differentiate plant-parasitic nematodes from other types that also occur in soil and plant tissue, and to identify them as to genus. Also included are 1500 citations of publications on the taxonomy of the 66 genera and on the general taxonomy of nematodes, particularly plant-parasitic nematodes. 224 pages, £6.35 (paper).

CORNELL UNIVERSITY PRESS 2-4 Brook Street, London W1 